\title{
Effects of a policosanol supplement on serum lipid concentrations in hypercholesterolaemic and heterozygous familial hypercholesterolaemic subjects
}

\author{
A. Greyling, C. De Witt, W. Oosthuizen and J. C. Jerling* \\ School of Physiology, Nutrition and Consumer Sciences, North-West University (Potchefstroom Campus), South Africa
}

(Received 28 June 2005 - Revised 28 November 2005 - Accepted 2 December 2005)

\begin{abstract}
Policosanol is a mixture of higher aliphatic primary alcohols that is extracted from purified sugar cane wax or a variety of other plant sources, and has been shown to have beneficial effects on serum lipid concentrations. The objective of this study was to investigate the effects of a policosanol supplement (Octa-60) on lipid profiles of hypercholesterolaemic and heterozygous familial hypercholesterolaemic subjects. Nineteen hypercholesterolaemic and familial hypercholesterolaemic subjects completed this randomised, placebo-controlled, double-blind study. The subjects received either a daily dose of $20 \mathrm{mg}$ policosanol or placebo for 12 weeks. After a wash-out period of 4 weeks, the interventions were crossed over. Lipid levels were measured at baseline and at the end of each intervention period. No significant differences in total cholesterol and LDL-cholesterol from baseline to end or between policosanol and placebo were seen in the hypercholesterolaemic or familial hypercholesterolaemic groups. There were small reductions in total cholesterol and LDL-cholesterol from baseline to end in the hypercholesterolaemic group, but these changes did not differ significantly from the changes with the placebo, indicating that the observed decrease in cholesterol in the policosanol group was not due to the specific effect of policosanol treatment. The differences in response may be ascribed to the differences in composition of the higher aliphatic primary alcohols in the previously used products, compared with the local policosanol supplement. An intake of $20 \mathrm{mg} / \mathrm{d}$ policosanol for $12 \mathrm{weeks}$ had no significant effect on serum lipid levels in hypercholesterolaemic and heterozygous familial hypercholesterolaemic patients when compared with placebo intake.
\end{abstract}

Policosanol: Lipids: Cholesterol: Familial hypercholesterolaemia

Policosanol is a natural mixture of higher aliphatic primary alcohols, extracted from purified sugar cane wax (Saccharum officinarum L.) by hydrolytic cleavage and subsequent purification. The mixture can also be obtained from a variety of other plant sources as well as beeswax. The major components of the mixture are octacosanol $(60-70 \% \mathrm{w} / \mathrm{w})$, triacocontanol $(10-15 \% \mathrm{w} / \mathrm{w})$ and hexacosanol $(4 \cdot 5-10 \% \mathrm{w} / \mathrm{w})$, with tetracosanol, heptacosanol, nonacosanol, dotriacontanol and tetratriacontanol making up the lesser constituents (Mas, 2000).

Numerous well-designed clinical studies have shown highly beneficial effects of policosanol on serum lipid levels. Studies on hypercholesterolaemic patients have shown that $10 \mathrm{mg}$ policosanol per day significantly lowered total cholesterol by between 14.1 and $18 \%$, and LDL-cholesterol (LDL-C) by between 21.1 and $27.5 \%$, while raising HDL-cholesterol (HDL-C) by 11.2-28.9\% (Pons et al. 1994; Aneiros et al. 1995; Canetti et al. 1995; Castano et al. 1997, 2002c). Policosanol has also shown similar efficacy in patients with type II diabetes (Torres et al. 1995; Crespo et al. 1997; Castano et al. 2003a) and in a number of animal models (Arruzazabala et al. 1994; Rodriguez-Echenique et al. 1994; Menendez et al. 1997). Policosanol appears to act in a dose-dependent manner (Janikula, 2002).
Of special interest in judging the efficacy of policosanol are trials in which the effects of established lipid-lowering medications, in this case statins, were compared with those of policosanol. A comparison of pravastatin (Benitez et al. 1997), lovastatin (Castano et al. 2000a; Crespo et al. 1999) and fluvastatin (Fernandez et al. 2001) against policosanol, in comparable dosages, showed that statins and policosanol lowered the total cholesterol to the same extent, whereas the decrease in LDL-C and the increase in HDL-C were more pronounced with policosanol treatment.

Toxicological studies in rats have shown that doses as high as $500 \mathrm{mg} / \mathrm{kg}$ body weight, which is 1724 times the recommended therapeutic dose, resulted in no reports of toxicity (Aleman et al. 1994). Doses of up to $5000 \mathrm{mg} / \mathrm{kg}$ did not show any evidence of oral toxicity (Gamez et al. 2001). Similarly, studies on carcinogenicity (Aleman et al. 1994, 1995), reproduction and teratogenicity (Rodriguez \& Garcia, 1994, 1998) did not show any adverse effects.

Most of the clinical studies on policosanol were, however, conducted at a limited number of centres. Thus, there is a need for the current data on policosanol to be confirmed by other laboratories in different populations (Gouni-Berthold \& Berthold, 2002; Janikula, 2002; Lin et al. 2004). 
The efficacy of policosanol in lowering LDL-C in familial hypercholesterolaemia has not yet been tested. These subjects present a major genetic dominant disorder caused by a mutation in the LDL receptor gene, resulting in elevated blood cholesterol concentrations and risk of CHD. The objective of this study was therefore to investigate the effects of a policosanol supplement (Octa-60; Garuda International Inc. Lemon cove, CA, USA; purified from sugar cane wax) on the serum lipid profiles of hypercholesterolaemic subjects and heterozygous subjects with familial hypercholesterolaemia.

\section{Methods}

Subjects

This study was conducted at the Lipid Clinic of the School of Physiology, Nutrition and Consumer Sciences of the NorthWest University, South Africa. Ethical approval to conduct the study was obtained from the ethical committee of the university (ethics no: 03M06).

Men and women were eligible to participate if they met the following criteria: age older than 21 years and with a serum total cholesterol concentration above $5 \mathrm{mmol} / \mathrm{l}$. Heterozygous familial hypercholesterolaemic subjects had to have a LDL receptor mutation on exon 4 or 9 of the LDL receptor gene or had to meet the diagnostic criteria for determining familial hypercholesterolaemia as stipulated by Defesche (Sauvage Nolting et al. 2003). Exclusion criteria included serum triacylglycerol levels above $2.5 \mathrm{mmol} / \mathrm{l}$, being a smoker, pregnancy or lactation, the use of anticoagulant medication or the use of aspirin in excess of $300 \mathrm{mg} / \mathrm{d}$.

Subjects using lipid-lowering medication (specifically statins) were included in the study for ethical reasons. Because of the very high total cholesterol and LDL-C concentrations in familial hypercholesterolaemic patients, almost all heterozygous familial hypercholesterolaemic patients need to take lipid-lowering medication to reach their target LDL-C levels (Civeira 2004). It is therefore not feasible to obtain a large subject group who are not using statins, and we viewed it as unethical to require subjects to discontinue their statin treatment. Subjects using statins had to have been stable on the medication for at least 3 months prior to inclusion in the study. They were instructed not to change their dosage or treatment regimen in any way for the duration of the study, and they had to comply with the inclusion criteria: namely, they had to have an increased total cholesterol concentration while using statins.

Forty-four hypercholesterolaemic (twenty-two of whom were familial hypercholesterolaemic) volunteers who regularly attend the lipid clinic were recruited as based on a power calculation using total cholesterol (Margetts \& Nelson, 1997), as measured in this population. Based on an expected LDL-C-lowering effect of at least $20 \%$ (Castano et al. 2002b, 2003c), this number of subjects would have provided at least $80 \%$ power at a $5 \%$ level of significance. The subjects signed informed consent forms for participation in the study. The baseline characteristics of the subjects can be seen in Table 1 .

Upon enrolment at the lipid clinic, all the subjects received dietary counselling regarding a dyslipidaemic diet (55\% energy as carbohydrates, $15 \%$ as protein and $30 \%$ as fat, with less than $10 \%$ energy intake in the form of saturated fat and less than $300 \mathrm{mg} / \mathrm{d}$ cholesterol) from a registered dietician, along with other lifestyle recommendations. All of the subjects had been attending the lipid clinic for at least 3 months, had a stable weight and were following their individually adapted diets as their normal routine.

Each subject received a calendar with important dates (e.g. when blood would be taken, etc.). They were asked to maintain their normal daily routine (eating pattern, physical activity, alcohol consumption) for the duration of the study. The subjects were also asked to keep a diary of illnesses and any changes in medication used (if absolutely necessary) during the study.

Subjects were asked to report any adverse effects. Adverse events were defined as 'mild' if cessation of the study treatment was not required and 'moderate' if a physician recommended specific treatment and/or discontinuation of the study treatment. Serious adverse events were defined as those being fatal or leading to prolonged hospitalisation.

Table 1. Subjects' baseline characteristics

\begin{tabular}{|c|c|c|c|c|}
\hline \multirow[b]{2}{*}{ Characteristics } & \multicolumn{2}{|c|}{ Familial hypercholesterolaemia } & \multicolumn{2}{|c|}{ Hypercholesterolaemia } \\
\hline & Mean & $95 \% \mathrm{Cl}$ & Mean & $95 \% \mathrm{Cl}$ \\
\hline Male & 2 & & 13 & \\
\hline Female & 14 & & 6 & \\
\hline Age (years) & 47 & $41 \cdot 6,52 \cdot 4$ & $51 \cdot 1$ & $46 \cdot 2,56 \cdot 0$ \\
\hline Weight (kg) & 72 & $65 \cdot 2,78 \cdot 5$ & 88 & $81 \cdot 9,93 \cdot 9$ \\
\hline Height (m) & 1.64 & $1.58,1.69$ & $1 \cdot 74$ & $1 \cdot 70,1 \cdot 78$ \\
\hline $\mathrm{BMI}\left(\mathrm{kg} / \mathrm{m}^{2}\right)$ & $26 \cdot 75$ & $24 \cdot 7,28 \cdot 8$ & $29 \cdot 1$ & $27 \cdot 2,31 \cdot 0$ \\
\hline Serum total cholesterol (mmol/l) & $6 \cdot 84$ & $6 \cdot 03,7 \cdot 65$ & $6 \cdot 37$ & $5 \cdot 94,6 \cdot 80$ \\
\hline Serum HDL-C (mmol/l) & $1 \cdot 16$ & $1 \cdot 03,1 \cdot 29$ & 1.09 & $0 \cdot 97,1 \cdot 21$ \\
\hline Serum LDL-C (mmol/l) & $5 \cdot 20$ & $4 \cdot 31,6 \cdot 09$ & $4 \cdot 34$ & $3 \cdot 99,4 \cdot 69$ \\
\hline Serum triacylglycerol (mmol/l) & $1 \cdot 31$ & $0.89,1.73$ & 1.92 & $1 \cdot 55,2 \cdot 30$ \\
\hline Statin use: & $n 10$ & & $n 3$ & \\
\hline $5 \mathrm{mg}$ & $n 1$ & & $n 1$ & \\
\hline $10 \mathrm{mg}$ & $n 0$ & & $n 1$ & \\
\hline $20 \mathrm{mg}$ & $n 8$ & & $n 1$ & \\
\hline $40 \mathrm{mg}$ & $n 1$ & & $n 0$ & \\
\hline
\end{tabular}

HDL-C, HDL-cholesterol; LDL-C, LDL-cholesterol. 


\section{Study design and protocol}

A randomised, placebo-controlled, double-blind, crossover study design was employed for this study.

Volunteers meeting the selection criteria were first divided into two groups (hypercholesterolaemic and familial hypercholesterolaemic) and then paired off according to use of lipid-lowering medication. The respective groups were then randomly assigned to either the active treatment or placebo using random numbers tables. Each treatment period lasted 12 weeks, with a washout period of 4 weeks employed between the two treatment periods.

Anthropometric measurements were taken before and every 3 weeks during the intervention period. BMI $\left(\mathrm{kg} / \mathrm{m}^{2}\right)$ was calculated.

\section{Supplements and placebos}

The policosanol supplement contained $20 \mathrm{mg}$ of the higher aliphatic primary alcohol mixture (purified from sugar cane wax) Lesstanol Octa-60 as the active ingredient as well as $400 \mu \mathrm{g}$ folic acid, and was supplied by MZL Investments cc (Cape Town, South Africa). The placebo was identical to the supplement but consisted of corn starch as well as $400 \mu \mathrm{g}$ folic acid. Subjects received one tablet per day of either the supplement or the placebo, which was taken after the evening meal owing to greater synthesis of cholesterol at night (Pappu \& Illingworth, 2002; Siavoshian et al. 1995).

\section{Blood samples}

A qualified nursing sister, using a 21-gauge scalp infusion set, collected venous blood samples after a $12 \mathrm{~h}$ overnight fast. Samples were drawn with minimum stasis between 07.00 and 10.00 hours to avoid the effects of diurnal variation. A $10 \mathrm{ml}$ blood sample was drawn and left to clot, after which the blood was centrifuged at $4000 \mathrm{rpm}$ for $15 \mathrm{~min}$ at $10^{\circ} \mathrm{C}$ to yield serum for lipid analysis. Serum was divided into aliquots and stored at $-82^{\circ} \mathrm{C}$ until analysis. Serum triacylglycerol, total cholesterol and HDL-C were measured using a Vitros DT60 II Chemistry Analyser (Ortho-Clinical Diagnostics, Rochester, NY, USA). Serum LDL-C was calculated using the formula of Friedewald et al. (1972).

\section{Compliance}

Compliance was determined by pill-counting. A dose of three, five or seven tablets were randomly added to each subject's given amount (twenty-one tablets every 3 weeks). This extra amount was recorded next to each subject's identity number on the file. Every 3 weeks, the left-over tablets were counted and compared with the number on file. Subjects were then interviewed and supplied with tablets for the next 3 weeks.

\section{Statistical analysis}

The computer software package Statistica (StatSoft ${ }^{\circledR}$ Ltd, Bedford, UK) was used for the statistical analysis. The variables were tested for normality using the Shapiro Wilk test. Significant differences within groups (from baseline to end) and between groups that were normally distributed were determined with the $t$ test for dependent variables. These variables are presented as means and $95 \%$ CI. A $P$ value $\leqslant 0.05$ was regarded as statistically significant. A nesteddesign ANOVA was used to determine whether the order of policosanol or placebo treatment influenced the results. Analysis of covariance was used to analyse the effects of treatment on changes in variables while controlling for the effects of baseline lipid concentrations and changes in BMI.

\section{Results}

The responses in terms of lipid variables for men and women did not differ from each other and always occurred in the same direction. The data were therefore analysed and reported for men and women combined. Data from the familial hypercholesterolaemic and hypercholesterolaemic groups are reported separately. There were no order-of-treatment effects.

\section{Dropouts}

Nine subjects were not included in the final statistical analysis; six were familial hypercholesterolaemic and three were hypercholesterolaemic. Two subjects changed the type of lipid-lowering medication they were using, and one subject stopped using statins. One subject started hormone replacement therapy. One subject's triacylglycerol levels rose above exclusion criteria values, possibly owing to weight gain. One subject's weight increased by $4.6 \mathrm{~kg}$ during the placebo phase, and three subjects abandoned the study for personal reasons. There was no indication that these subjects were in any way different from those who completed the study.

\section{Compliance}

Overall compliance with policosanol pill intake during the study was very good. Estimations of compliance for the two groups were $94.03 \%$ for the supplement and $90.44 \%$ for the placebo in the familial hypercholesterolaemic group, and $91.48 \%$ for the supplement and $94.87 \%$ for the placebo in the hypercholesterolaemic group.

\section{Safety and tolerability}

Four adverse events were reported during the study. All were classified as mild events, and no patient withdrew from the study because of adverse events. Three of the events, which included two cases of headache and one case of vertigo, were reported during policosanol intake. One adverse event (fluid retention) was reported with the placebo treatment. Similar adverse events have been reported in other studies. In all cases, however, these events involved less than $1 \%$ of the population (Fernandez et al. 1998; Mas et al. 1999b). It therefore seems highly unlikely that the adverse events can be ascribed to the use of the policosanol supplement.

\section{Effects of policosanol on serum lipid levels}

Changes in serum lipid levels and body weight are summarised in Table 2 for the familial hypercholesterolaemic group and Table 3 for the hypercholesterolaemic group. There was a statistically significant increase of $0.27 \mathrm{~kg} / \mathrm{m}^{2}$ BMI and 
Table 2. Mean $(95 \% \mathrm{Cl})$ changes in familial hypercholesterolaemic subjects $(n 16)$

\begin{tabular}{|c|c|c|c|c|c|c|c|}
\hline \multirow[b]{2}{*}{ Variable } & \multicolumn{2}{|c|}{ Policosanol } & \multirow{2}{*}{$\begin{array}{l}P \text { value (difference } \\
\text { within group) }\end{array}$} & \multicolumn{2}{|c|}{ Placebo } & \multirow{2}{*}{$\begin{array}{l}P \text { value (difference } \\
\text { within group) }\end{array}$} & \multirow{2}{*}{$\begin{array}{c}P \text { value(difference } \\
\text { between groups) }\end{array}$} \\
\hline & Mean & $95 \% \mathrm{Cl}$ & & Mean & $95 \% \mathrm{Cl}$ & & \\
\hline \multicolumn{8}{|l|}{ Weight (kg) } \\
\hline Baseline & 71.58 & $65 \cdot 22,77 \cdot 95$ & 0.002 & $71 \cdot 83$ & $65 \cdot 2,78 \cdot 45$ & 0.31 & \\
\hline End & $72 \cdot 33$ & $65 \cdot 80,78 \cdot 85$ & & $72 \cdot 15$ & $65 \cdot 48,78 \cdot 83$ & & \\
\hline Baseline - end & 0.74 & $0 \cdot 32,1 \cdot 16$ & & 0.33 & $-0.34,1 \cdot 00$ & & 0.36 \\
\hline \multicolumn{8}{|l|}{ BMI $\left(\mathrm{kg} / \mathrm{m}^{2}\right)$} \\
\hline End & $26 \cdot 95$ & $24 \cdot 88,29 \cdot 02$ & & $26 \cdot 88$ & $24 \cdot 77,28 \cdot 98$ & & \\
\hline Baseline - end & 0.27 & $0.11,0.42$ & & 0.13 & $-0.13,0.39$ & & 0.42 \\
\hline \multicolumn{8}{|c|}{ Total cholesterol (mmol/l) } \\
\hline Baseline & $7 \cdot 14$ & $6 \cdot 18,8 \cdot 09$ & 0.72 & $6 \cdot 84$ & $6 \cdot 03,7 \cdot 65$ & 0.44 & \\
\hline End & $7 \cdot 21$ & $6 \cdot 26,8 \cdot 15$ & & $7 \cdot 07$ & $6 \cdot 11,8 \cdot 03$ & & \\
\hline Baseline - end & 0.07 & $-0.34,0 \cdot 49$ & & 0.23 & $-0.39,0 \cdot 85$ & & 0.67 \\
\hline \multicolumn{8}{|l|}{ HDL-C (mmol/l) } \\
\hline Baseline & $1 \cdot 22$ & $1 \cdot 10,1 \cdot 34$ & 0.58 & $1 \cdot 16$ & $1 \cdot 03,1 \cdot 29$ & 0.35 & \\
\hline \multicolumn{8}{|l|}{ LDL-C (mmol/l) } \\
\hline Baseline & $5 \cdot 30$ & $4 \cdot 34,6 \cdot 27$ & 0.47 & $5 \cdot 20$ & $4 \cdot 31,6 \cdot 09$ & 0.88 & \\
\hline End & 5.47 & $4 \cdot 56,6 \cdot 38$ & & $5 \cdot 25$ & $4 \cdot 26,6 \cdot 23$ & & \\
\hline Baseline - end & 0.16 & $-0.31,0.64$ & & 0.05 & $-0 \cdot 62,0 \cdot 71$ & & 0.77 \\
\hline \multicolumn{8}{|c|}{ Triacylglycerol (mmol/l) } \\
\hline Baseline & 1.43 & $0.92,1.94$ & 0.14 & $1 \cdot 31$ & $0.89,1 \cdot 73$ & 0.88 & \\
\hline End & 1.29 & $0 \cdot 89,1.68$ & & 1.32 & $0.93,1 \cdot 71$ & & \\
\hline Baseline - end & -0.14 & $-0.34,0 \cdot 06$ & & 0.01 & $-0 \cdot 17,0 \cdot 19$ & & 0.16 \\
\hline
\end{tabular}

HDL-C, HDL-cholesterol; LDL-C, LDL-cholesterol.

Table 3. Mean $(95 \% \mathrm{Cl})$ changes in hypercholesterolaemic subjects $(n 19)$

\begin{tabular}{|c|c|c|c|c|c|c|c|}
\hline \multirow[b]{2}{*}{ Variable } & \multicolumn{2}{|c|}{ Policosanol } & \multirow{2}{*}{$\begin{array}{l}P \text { value (difference } \\
\text { within group) }\end{array}$} & \multicolumn{2}{|c|}{ Placebo } & \multirow{2}{*}{$\begin{array}{l}P \text { value (difference } \\
\text { within group) }\end{array}$} & \multirow{2}{*}{$\begin{array}{c}P \text { value (difference } \\
\text { between groups) }\end{array}$} \\
\hline & Mean & $95 \% \mathrm{Cl}$ & & Mean & $95 \% \mathrm{Cl}$ & & \\
\hline \multicolumn{8}{|l|}{ Weight (kg) } \\
\hline Baseline & $88 \cdot 14$ & $82 \cdot 08,94 \cdot 21$ & 0.48 & $87 \cdot 89$ & $81 \cdot 93,93 \cdot 86$ & 0.09 & \\
\hline End & 87.93 & $81 \cdot 64,94 \cdot 21$ & & 88.30 & $82 \cdot 17,94 \cdot 43$ & & \\
\hline Baseline - end & -0.22 & $-0.84,0.41$ & & 0.40 & $-0.07,0.88$ & & 0.08 \\
\hline \multicolumn{8}{|l|}{ BMI $\left(\mathrm{kg} / \mathrm{m}^{2}\right)$} \\
\hline End & $29 \cdot 10$ & $27 \cdot 14,31 \cdot 05$ & & $29 \cdot 23$ & $27 \cdot 29,31 \cdot 16$ & & \\
\hline Baseline - end & -0.07 & $-0 \cdot 28,0 \cdot 13$ & & 0.13 & $-0.03,0.29$ & & 0.08 \\
\hline \multicolumn{8}{|c|}{ Total cholesterol $(\mathrm{mmol} / \mathrm{l})$} \\
\hline Baseline & 6.56 & $6 \cdot 19,6 \cdot 93$ & 0.03 & $6 \cdot 37$ & $5 \cdot 95,6 \cdot 80$ & 0.77 & \\
\hline End & $6 \cdot 16$ & $5 \cdot 75,6 \cdot 57$ & & $6 \cdot 32$ & $5 \cdot 91,6 \cdot 74$ & & \\
\hline Baseline - end & -0.40 & $-0.77,0.03$ & & -0.05 & $-0.37,0 \cdot 28$ & & 0.18 \\
\hline \multicolumn{8}{|l|}{ HDL-C (mmol/l) } \\
\hline Baseline & 1.09 & $0.98,1 \cdot 21$ & 0.16 & 1.09 & $0 \cdot 97,1 \cdot 21$ & 0.77 & \\
\hline \multicolumn{8}{|l|}{ LDL-C (mmol/l) } \\
\hline Baseline & 4.63 & $4 \cdot 32,4 \cdot 95$ & 0.009 & $4 \cdot 34$ & $3 \cdot 99,4 \cdot 69$ & 0.61 & \\
\hline End & $4 \cdot 24$ & $3 \cdot 84,4 \cdot 64$ & & 4.23 & $3 \cdot 72,4 \cdot 75$ & & \\
\hline Baseline - end & -0.40 & $-0 \cdot 68,0 \cdot 11$ & & -0.11 & $-0.54,0.32$ & & 0.22 \\
\hline \multicolumn{8}{|c|}{ Triacylglycerol (mmol/l) } \\
\hline Baseline & 1.88 & $1 \cdot 53,2 \cdot 23$ & 0.44 & 1.92 & $1 \cdot 55,2 \cdot 30$ & 0.44 & \\
\hline End & $2 \cdot 06$ & $1 \cdot 57,2 \cdot 54$ & & $2 \cdot 06$ & $1.55,2.57$ & & \\
\hline Baseline - end & $0 \cdot 18$ & $-0.30,0.66$ & & 0.14 & $-0.23,0.51$ & & 0.88 \\
\hline
\end{tabular}

HDL-C, HDL-cholesterol; LDL-C, LDL-cholesterol.

$0.74 \mathrm{~kg}$ body weight in the familial hypercholesterolaemic group during policosanol treatment (Table 2). This change was very small and probably not of clinical significance. It has been shown in metabolic ward studies that a change of $1 \mathrm{~kg} / \mathrm{m}^{2}$ BMI results in a small change of $0.2 \mathrm{mmol} / \mathrm{l}$ serum cholesterol (McNamara, 1994).
Supplementation with policosanol had no effect on total cholesterol, LDL-C, HDL-C or triacylglycerol in familial hypercholesterolaemic patients (Table 2). After controlling for the possible effect of lipid concentration at baseline and changes in BMI, there were still no significant differences between groups with regard to lipid concentration. 
In the hypercholesterolaemic group, BMI remained constant, and policosanol supplementation resulted in significant decreases, from baseline to end, of $6 \%$ in total cholesterol and $9 \%$ in LDL-C (Table 3). However, no statistically significant differences between the changes with the placebo and policosanol treatments were shown for total cholesterol or LDL-C concentration. After controlling for the possible effect of changes in BMI and lipid concentration at baseline, the differences between the groups were still not statistically significant. No effects on HDL-C and triacylglycerol were noted.

The response in lipid variables between statin users and non-users did not differ in any of the groups. The same results were achieved when the statin users were excluded from the data analysis in the hypercholesterolaemic group (this was not done for the familial hypercholesterolaemic group because of the small number). In addition, it is clear from Fig. 1, which illustrates the individual changes in LDL-C concentration during the interventions, that the concomitant use of statins by some of the subjects did not influence the changes in LDL-C concentration compared with non-users. The total cholesterol concentrations displayed a similar response. From Fig. 1, it can also be seen that the number of subjects who showed a decrease in, increase in or lack of effect on LDL-C concentration with intake of policosanol were approximately the same as with the intake of placebo.

\section{Discussion}

The salient observation of this double-blind, randomised, placebo-controlled, crossover study was that supplementation with $20 \mathrm{mg} / \mathrm{d}$ policosanol for 12 weeks did not have any effect on serum lipid levels in a group of free-living familial hypercholesterolaemic subjects. In the hypercholesterolaemic subjects, policosanol decreased total cholesterol and LDL-C levels from baseline to end by 6 and $9 \%$, respectively. These changes were, however, not significant when compared with placebo treatment. Policosanol treatment had no effect on HDL-C and triacylglycerol levels.
These results are in contrast to previous intervention studies that have shown highly beneficial effects of policosanol on serum lipid levels (Pons et al. 1994; Aneiros et al. 1995; Canetti et al. 1995; Torres et al. 1995; Castano et al. 1997; 2003a; 2002c; Crespo et al. 1997). Our results are, however, in agreement with those of Lin et al. (2004), who found that wheat germ policosanol failed to lower plasma cholesterol in subjects with normal to mildly elevated cholesterol concentrations. In recent animal studies, it has been shown that policosanol derived from rice, sunflower and sugar cane wax had no significant effects on plasma lipid levels in hamsters (Wang et al. 2003) or rabbits (Murphy et al. 2004).

The clinically effective dose range for policosanol has been determined to be $5-20 \mathrm{mg} / \mathrm{d}$ (Mas, 2000). Dosages of $5-10 \mathrm{mg} / \mathrm{d}$ were found to produce significant lipid-lowering effects (Pons et al. 1994; Aneiros et al. 1995; Canetti et al. 1995; Castano et al. 1997, 2002c). In this study, a daily dose of $20 \mathrm{mg}$ was employed; it is therefore unlikely that the lack of a cholesterol-lowering effect was the result of too low a dose being ingested.

Although it is unlikely, the possibility that this population group might have reacted differently to policosanol supplementation from the other population groups in which significant lipid-lowering effects were reported cannot, however, be excluded.

Little is known about the mechanism of the lipid-lowering actions of policosanol. It has been suggested that policosanol has an effect on 3-hydroxy-3-methylglutaryl coenzyme A (HMG-CoA) reductase, the rate-controlling enzyme in cholesterol biosynthesis. The inhibition of enzyme upregulation by policosanol suggests that it depresses the de novo synthesis of HMG-CoA reductase and/or stimulates its degradation. The exact mechanism by which policosanol inhibits the activity of HMG-CoA reductase still remains unclear (Janikula, 2002; Menendez et al. 1994, 1997, 2001). We hypothesized that policosanol might display a lipid-lowering effect in these subjects because of its potential to inhibit HMG-CoA reductase.

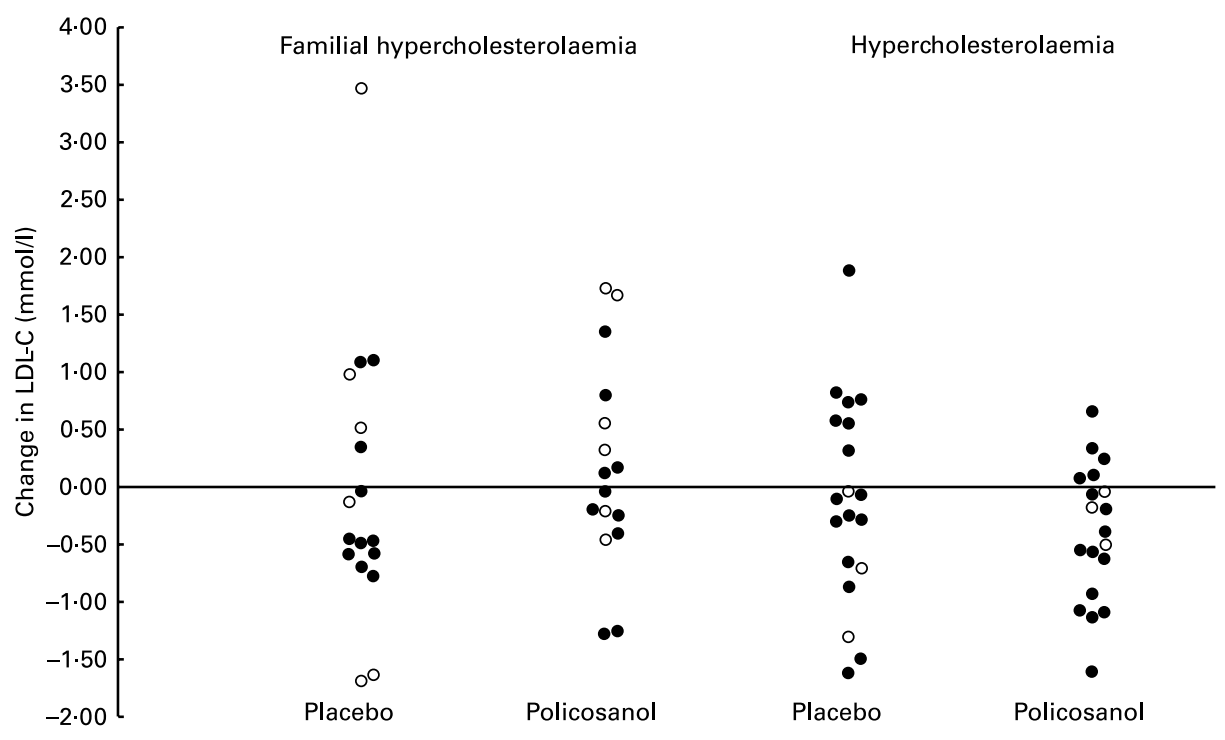

Fig. 1. Individual changes in LDL-cholesterol concentration $\circ$, Stain users; $\bullet$, Non-stain users. 
This hypothesis that policosanol operates by means of HMG-CoA reductase inhibition has, however, not yet been conclusively proven. Studies supporting this hypothesis have either been in vitro studies (Menendez et al. 1994, 2001; Lin et al. 2004) or animal studies (Menendez et al. 1996, 1997), and a recent study by Wang et al. (2003) has cast doubt on this hypothesis. Furthermore, it has been shown that the absorption of policosanol in the small intestine is low (Hargrove et al. 2004), placing some further doubt on the proposed HMG-CoA reductase mechanism.

It could be argued that the concomitant use of policosanol and statins (HMG-CoA reductase inhibitors), especially in the familial hypercholesterolaemic group, could have influenced the total cholesterol- and LDL-C-lowering ability of policosanol. To date, no studies evaluating the effects of a combined use of policosanol and statins have been published. As discussed above, the inhibitory effects of policosanol on HMG-CoA reductase in vivo have not yet been proved. It is clear from Fig. 1, illustrating the individual changes in LDL-C, that the concomitant use of HMGCoA reductase inhibitors (in this case, statins) and policosanol did not confound the results.

It has also been speculated that, since the overall absorption of policosanol is low but its effects have been reported to be substantial, it could have a lipid-lowering effect at the level of the intestine (Gouni-Berthold \& Berthold, 2002).

An important influential factor to consider is the composition of the mixture of higher aliphatic primary alcohols. Most of the evidence for a hypolipidaemic effect of policosanol originates from one centre (Janikula, 2002; Varady et al. 2003). There are, however, numerous products currently globally available that are being marketed as 'policosanol'. These products all claim measures of efficacy based on research carried out in this single centre even though their composition might be different from that of the originally patented product. Table 4 provides a summary of all the studies that have reported the composition of the policosanol supplements used, along with their effects on lipid concentrations, including the current study.

The current study, along with others (Wang et al. 2003; Lin et al. 2004) that failed to show a hypolididaemic effect, used policosanol supplements that differed slightly in composition from the policosanol supplement (Laboratorios Dalmer, Havana, Cuba) used in studies that did demonstrate lipid-lowering effects. Numerous other studies have also demonstrated lipid-lowering effects with this same supplement (Pons et al. 1994,1997; Aneiros et al. 1995; Canetti et al. 1995, 1997; Castano et al. 1995a,b, 1996, 1997, 1998, 1999a,b, 2000a,b 2001a,b,c, 2002a,b,c,d, 2003a,b,c; Batista et al. 1996; Benitez et al. 1997; Crespo et al. 1997, 1999; Ortensi et al. 1997; Mas et al. 1999a, 2001; Marcello et al. 2000; Fernandez et al. 2001; Mirkin et al. 2001).

A comparative study of Octa-60 from Garuda International Inc. (similar to our product) and policosanol from Dalmer Laboratories (the originally patented product) by Castano and co-workers reported significantly greater reductions in total cholesterol and LDL-C with policosanol from Dalmer compared with Octa-60 (policosanol: $20.4 \%$ decrease in total cholesterol, $30.2 \%$ decrease in LDL-C; Octa-60: $8.7 \%$ decrease in total cholesterol, $10 \%$ decrease in LDL-C; Castano et al. 2002a).

Octacosanol, which is present in the highest concentration $(>60 \%)$ in most of the higher primary aliphatic alcohol mixtures, is thought to be the active ingredient responsible for the

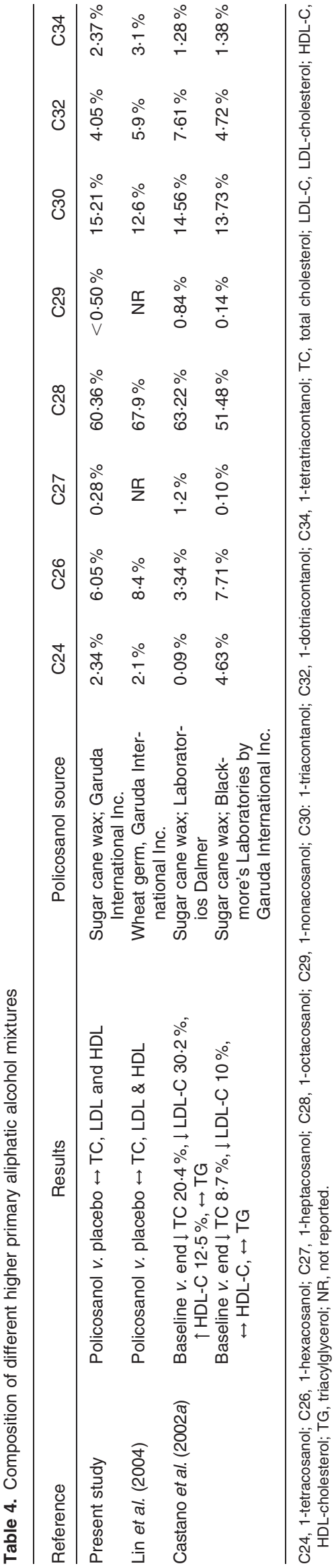


lipid-lowering actions of policosanol (Mas, 2000). However, the present study, as well as other studies using mixtures that contained sufficient amounts of octacosanol, could not demonstrate a significant lipid-lowering effect (Wang et al. 2003; Lin et al. 2004; Murphy et al. 2004). In light of this, it might be reasoned that the minor components in the mixture might play a more important role with regard to the lipid-lowering properties of policosanol than was previously thought. If, however, this assumption is true, the minor components must have a very powerful cholesterol-lowering effect based on the amount in $20 \mathrm{mg}$ policosanol.

\section{Conclusion}

In conclusion, a dose of $20 \mathrm{mg} / \mathrm{d}$ of a mixture of higher aliphatic primary alcohols, Octa-60, displayed no beneficial effects on the serum lipid profiles of the subjects in the present study. Although there is a large body of sound clinical evidence supporting the lipid-lowering efficacy of one mixture of higher aliphatic primary alcohols, similar mixtures do not seem to display similar effects. There is a definite need to conduct comparative multicentre trials examining the lipid-lowering efficacy of all the currently produced mixtures of higher aliphatic primary alcohols.

\section{Acknowledgements}

We would like to thank Mr Ivan Zuck from MZL Investments for funding this study and Sister Chrissie Lessing for her invaluable work in recruiting the test subjects and collecting the blood samples and other data.

\section{References}

Aleman CL, Mas R, Hernandez C, Rodeiro I, Cerejido E, Noa M, Capote A, Menendez R, Amor A \& Fraga V (1994) A 12-month study of policosanol oral toxicity in Sprague Dawley rats. Toxicol Lett 70, 77-87.

Aleman CL, Puig MN, Elias EC, Ortega CH, Guerra IR, Ferreiro RM \& Brinis F (1995) Carcinogenicity of policosanol in mice: an 18month study. Food Chem Toxicol 33, 573-578.

Aneiros E, Mas R, Calderon B, Illnait J, Fernandez L, Castano G \& Fernandez JC (1995) Effect of policosanol in lowering cholesterol levels in patients with type II hypercholesterolemia. Curr Ther Res 56, $176-182$.

Arruzazabala ML, Carbajal D, Mas R, Molina V, Valdes S \& Laguna A (1994) Cholesterol-lowering effects of policosanol in rabbits. Biol Res 27, 205-208.

Batista J, Stusser R, Saez F \& Perez B (1996) Effect of policosanol on hyperlipidemia and coronary heart disease in middle-aged patients. A 14-month pilot study. Int J Clin Pharmacol Ther 34, 134-137.

Benitez M, Romero C, Mas R, Fernandez L \& Fernandez JC (1997) A comparative study of policosanol versus pravastatin in patients with type II hypercholesterolemia. Curr Ther Res 58, 859-867.

Canetti MM, Moreira M, Mas R, Illnait J, Fernandez L \& Fernandez JC (1997) Effects of policosanol on primary hypercholesterolemia: a 3-year open-extension follow-up. Curr Ther Res 58, $868-875$.

Canetti M, Moreira M, Mas R, Illnait J, Fernandez L, Fernandez J, Diaz E \& Castano G (1995) A two-year study on the efficacy and tolerability of policosanol in patients with type II hyperlipoproteinaemia. Int J Clin Pharmacol Res 15, 159-165.
Castano G, Canetti M, Moreira M, Tula L, Mas R, Illnait J, Fernandez L, Fernandez JC \& Diaz E (1995a) Efficacy and tolerability of policosanol in elderly patients with type II hypercholesterolemia: a 12-month study. Curr Ther Res 56, 819-828.

Castano G, Fernandez L, Mas R, Illnait J, Fernandez J, Mesa M, Alvarez E \& Lezcay M (2002a) Comparison of the efficacy, safety and tolerability of original policosanol versus other mixtures of higher aliphatic primary alcohols in patients with type II hypercholesterolemia. Int J Clin Pharmacol Res 22, 55-66.

Castano G, Fernandez L, Mas R, Illnait J, Mesa M \& Fernandez JC (2003a) Comparison of the effects of policosanol and atorvastatin on lipid profile and platelet aggregation in patients with dyslipidaemia and type 2 diabetes mellitus. Clin Drug Invest 23, 639-650.

Castano G, Mas R, Arruzazabala ML, Noa M, Illnait J, Fernandez JC, Molina V \& Menendez A (1999a) Effects of policosanol and pravastatin on lipid profile, platelet aggregation and endothelemia in older hypercholesterolemic patients. Int J Clin Pharmacol Res 19, $105-116$.

Castano G, Mas R, Cesar Fernandez J, Pontigas V, Suazo M \& Fernandez L (1998) Open-label study of the efficacy, safety, and tolerability of policosanol in patients with high global coronary risk. Curr Ther Res 59, 737-745.

Castano G, Mas R, Fernandez JC, Fernandez L, Alvarez E \& Lezcay M (2000a) Efficacy and tolerability of policosanol compared with lovastatin in patients with type II hypercholesterolemia and concomitant coronary risk factors. Curr Ther Res 61, 137-146.

Castano G, Mas R, Fernandez JC, Fernandez L, Illnait J \& Lopez E (2002b) Effects of policosanol on older patients with hypertension and type II hypercholesterolaemia. Drugs RD 3, 159-172.

Castano G, Mas R, Fernandez L, Fernandez JC, Illnait J, Lopez LE \& Alvarez E (2000b) Effects of policosanol on postmenopausal women with type II hypercholesterolemia. Gynecol Endocrinol 14, 187-195.

Castano G, Mas R, Fernandez JC \& Illnait J (1997) Comparative effects of two once-daily regimens of policosanol in patients with type II hypercholesterolemia. Curr Ther Res 58, 154-162.

Castano G, Mas R, Fernandez JC, Illnait J, Fernandez L \& Alvarez E (2001a) Effects of policosanol in older patients with type II hypercholesterolemia and high coronary risk. J Gerontol A Biol Sci Med Sci 56, M186-M192.

Castano G, Mas R, Fernandez L, Illnait J, Gamez R \& Alvarez E (2001b) Effects of policosanol 20 versus $40 \mathrm{mg} /$ day in the treatment of patients with type II hypercholesterolemia: a 6-month double-blind study. Int J Clin Pharmacol Res 21, 43-57.

Castano G, Mas R, Fernandez L, Illnait J, Gamez R \& Fernandez JC (2001c) Comparison of two regimens of policosanol administered at $20 \mathrm{mg} / \mathrm{d}$ in patients with type II hypercholesterolemia: a randomized, double-blind, placebo-controlled study. Curr Ther Res 62, 194-208.

Castano G, Mas R, Fernandez L, Illnait J, Hernandez E, Fernandez JC, Gamez R, Gutierrez C \& Alvarez E (2002c) A randomized, double-blind, placebo-controlled study of the efficacy and tolerability of policosanol in adolescents with type II hypercholesterolemia. Curr Ther Res 63, 286-303.

Castano G, Mas R, Fernandez L, Illnait J, Mesa M, Alvarez E \& Lezcay M (2003b) Comparison of the efficacy and tolerability of policosanol with atorvastatin in elderly patients with type II hypercholesterolaemia. Drugs Aging 20, 153-163.

Castano G, Mas R, Fernandez JC, Lopez LE \& Fernandez L (1999b) A long-term, open-label study of the efficacy and tolerability of policosanol in patients with high global coronary risk. Curr Ther Res 60, 379-391.

Castano G, Mas R, Fernandez J, Lopez E, Illnait J, Fernandez L \& Mesa M (2003c) Effects of policosanol on borderline to mildly elevated serum total cholesterol levels: a prospective, doubleblind, placebo-controlled, parallel-group, comparative study. Curr Ther Res 64, 522-537. 
Castano G, Mas R, Nodarse M, Illnait J, Fernandez L \& Fernandez JC (1995b) One-year study of the efficacy and safety of policosanol ( $5 \mathrm{mg}$ twice daily) in the treatment of type II hypercholesterolemia. Curr Ther Res 56, 296-304.

Castano G, Menendez R, Mas R, Amor A, Fernandez JL, Gonzalez RL, Lezcay M \& Alvarez E (2002d) Effects of policosanol and lovastatin on lipid profile and lipid peroxidation in patients with dyslipidemia associated with type 2 diabetes mellitus. Int $J$ Clin Pharmacol Res 22, 89-99.

Castano G, Tula L, Canetti M, Morera M, Mas R, Illnait J, Fernandez L \& Fernandez JC (1996) Effects of policosanol in hypertensive patients with type II hypercholesterolemia. Curr Ther Res 57, 691-699.

Civeira F. (2004) Guidelines for the diagnosis and management of heterozygous familial hypercholesterolemia. Atherosclerosis 173, $55-68$.

Crespo N, Alvarez R, Mas R, Illnait J, Fernandez L \& Fernandez JC (1997) Effects of policosanol on patients with non-insulin-dependent diabetes mellitus and hypercholesterolemia: a pilot study. Curr Ther Res 58, 44-51.

Crespo N, Illnait J, Mas R, Fernandez L, Fernandez J \& Castano G (1999) Comparative study of the efficacy and tolerability of policosanol and lovastatin in patients with hypercholesterolemia and noninsulin dependent diabetes mellitus. Int J Clin Pharmacol Res 19, $117-127$.

Fernandez JC, Mas R, Castano G, Menendez R, Amor AM, Gonzalez RM \& Alvarez E (2001) Comparison of the efficacy, safety and tolerability of policosanol versus fluvastatin in elderly hypercholesterolaemic women. Clin Drug Investig 21, 103-113.

Fernandez L, Mas R, Illnait J \& Fernandez JC (1998) Policosanol: results of a postmarketing surveillance study of 27,879 patients. Curr Ther Res 59, 717-722.

Friedewald WT, Levy RI \& Fredrickson DS (1972) Estimation of the concentration of low-density lipoprotein cholesterol in plasma, without use of the preparative ultracentrifuge. Clin Chem 18, 499-502.

Gamez R, Aleman CL, Mas R, Noa M, Rodeiro I, Garcia H, Hernandez C, Menendez R \& Aguilar C (2001) A 6-month study on the toxicity of high doses of policosanol orally administered to Sprague-Dawley rats. J Med Food 4, 57-65.

Gouni-Berthold I \& Berthold HK (2002) Policosanol: clinical pharmacology and therapeutic significance of a new lipid-lowering agent. Am Heart J 143, 356-365.

Hargrove JL, Greenspan P \& Hartle DK (2004) Nutritional significance and metabolism of very long chain fatty alcohols and acids from dietary waxes. Exp Biol Med (Maywood) 229, 215-226.

Janikula M (2002) Policosanol: a new treatment for cardiovascular disease? Altern Med Rev 7, 203-217.

Lin Y, Rudrum M, van der Wielen RP, Trautwein EA, McNeill G, Sierksma A \& Meijer GW (2004) Wheat germ policosanol failed to lower plasma cholesterol in subjects with normal to mildly elevated cholesterol concentrations. Metabolism 53, 1309-1314.

McNamara DJ (1994) Cardiovascular disease. In: Modern nutrition in health and disease, pp. 1533-1544 [ME Shils, JA Olson and M Shike, editors]. Philodelphia: Lea and Febiger.

Marcello S, Gladstein J, Tesone P \& Mas R (2000) Effects of bezafibrate plus policosanol or placebo in patients with combined dyslipidemia: a pilot study. Curr Ther Res 61, 346-357.

Margetts B \& Nelson M (1997) Design Concepts in Nutritional Epidemiology, 2nd edn. Oxford: Oxford University Press.

Mas R (2000) Policosanol. Hypolipidemic antioxidant treatment of atherosclerosis. Drugs Future 25, 569-586.

Mas R, Castano G, Fernandez L, Illnait J, Fernandez J \& Alvarez E (2001) Effects of policosanol on lipid profile and cardiac events in older hypercholesterolaemic patients with coronary disease. Clin Drug Invest 21, 485-497.

Mas R, Castano G, Illnait J, Fernandez L, Fernandez J, Aleman C, Pontigas V \& Lescay M (1999a) Effects of policosanol in patients with type II hypercholesterolemia and additional coronary risk factors. Clin Pharmacol Ther 65, 439-447.

Mas R, Rivas P, Izquierdo JE, Hernandez R, Fernandez L, Fernandez J, Orta SD, Illnait J \& Ricardo Y (1999b) Pharmacoepidemiologic study of policosanol. Curr Ther Res 60, 458-467.

Menendez R, Amor AM, Gonzalez RM, Fraga V \& Mas R (1996) Effect of policosanol on the hepatic cholesterol biosynthesis of normocholesterolemic rats. Biol Res 29, 253-257.

Menendez R, Amor AM, Rodeiro I, Gonzalez RM, Gonzalez PC, Alfonso JL \& Mas R (2001) Policosanol modulates HMG-CoA reductase activity in cultured fibroblasts. Arch Med Res 32, 8-12.

Menendez R, Arruzazabala L, Mas R, et al. (1997) Cholesterollowering effect of policosanol on rabbits with hypercholesterolaemia induced by a wheat starch-casein diet. Br J Nutr 77, 923-932.

Menendez R, Fernandez SI, Del Rio A, Gonzalez RM, Fraga V, Amor AM \& Mas RM (1994) Policosanol inhibits cholesterol biosynthesis and enhances low density lipoprotein processing in cultured human fibroblasts. Biol Res 27, 199-203.

Mirkin A, Mas R, Martinto M, Boccanera R, et al. (2001) Efficacy and tolerability of policosanol in hypercholesterolemic postmenopausal women. Int J Clin Pharmacol Res. 21, 31-41.

Murphy KJ, Saint DA \& Howe PR (2004) Lack of effect of sugar cane and sunflower seed policosanols on plasma cholesterol in rabbits. Asia Pac J Clin Nutr 13, S69.

Ortensi G, Julio G, Hector V \& Pedro AT (1997) A comparative study of policosanol versus simvastatin in elderly patients with hypercholesterolemia. Curr Ther Res 58, 390-401.

Pappu AS \& Illingworth DR (2002) The effects of lovastatin and simvastatin on the diurnal periodicity of plasma mevalonate concentrations in patients with heterozygous familial hypercholesterolemia. Atherosclerosis 165, 137-144.

Pons P, Illnait J, Mas R, Rodriguez M, Aleman C, Cesar Fernandez J, Fernandez L \& Martin M (1997) A comparative study of policosanol versus probucol in patients with hypercholesterolemia. Curr Ther Res 58, 26-35.

Pons P, Rodriguez M, Robaina C, Illnait J, Mas R, Fernandez L \& Fernandez JC (1994) Effects of successive dose increases of policosanol on the lipid profile of patients with type II hypercholesterolaemia and tolerability to treatment. Int J Clin Pharmacol Res 14, $27-33$.

Rodriguez MD \& Garcia H (1994) Teratogenic and reproductive studies of policosanol in the rat and rabbit. Teratog Carcinog Mutagen 14, 107-113.

Rodriguez MD \& Garcia H (1998) Evaluation of peri- and post-natal toxicity of Policosanol in rats. Teratog Carcinog Mutagen 18, 1-7.

Rodriguez-Echenique C, Mesa R, Mas R, Noa M, Menendez R, Gonzalez RM, Amor AM, Fraga V, Sotolongo V \& Laguna A (1994) Effects of policosanol chronically administered in male monkeys (Macaca arctoides). Food Chem Toxicol 32, $565-575$.

Sauvage Nolting PR, Defesche JC, Buirma RJ, Hutten BA, Lansberg PJ \& Kastelein JJ (2003) Prevalence and significance of cardiovascular risk factors in a large cohort of patients with familial hypercholesterolaemia. J Intern Med 253, 161-168.

Siavoshian S, Simoneau C, Maugeais P, Marks L, Rodary L, Gardette J \& Krempf M (1995) Measurement of mevalonic acid in human urine by bench top gas chromatography-mass spectrometry. Clin Chim Acta 243, 129-136.

Torres O, Agramonte AJ, Illnait J, Mas Ferreiro R, Fernandez L \& Fernandez JC (1995) Treatment of hypercholesterolemia in NIDDM with policosanol. Diabetes Care 18, 393-397.

Varady KA, Wang Y \& Jones PJH (2003) Role of policosanols in the prevention and treatment of cardiovascular disease. Nutr Rev. 61 376-383.

Wang YW, Jones PJH, Pischel I \& Fairow C (2003) Effects of policosanols and phytosterols on lipid levels and cholesterol biosynthesis in hamsters. Lipids 38, 165-170. 